\title{
EVALUATION AND COMPARISON OF SURFACE MACROTEXTURE AND FRICTION MEASUREMENT METHODS
}

\author{
Halil SEZEN $^{\mathrm{a}}$, Nicholas FISCO ${ }^{\mathrm{b}}$ \\ ${ }^{a}$ Department of Civil and Environmental Engineering and Geodetic Science, The Ohio State University, \\ Columbus, OH 43210, USA \\ ${ }^{b}$ TranSystems Corporation, Cleveland, OH, USA
}

Received 18 Aug. 2011; accepted 27 Sep. 2011

\begin{abstract}
Two- and three-dimensional macrotexture characteristics of various surfaces were measured using five different testing methods including sand patch method, laser profiler, laser texture scanner, circular texture meter, and x-ray computed tomography (CT) scanning. A dynamic friction tester was also used to measure the friction resistance of the same surfaces. Asphalt and Portland cement concrete samples of various mix designs and finishes and other commonly manufactured textured samples were used. Relationship between the macrotexture and friction was investigated. Mean texture depth (MTD) of 26 laboratory specimens was obtained from volumetric sand patch tests. Two-dimensional profiles and mean profile depth (MPD) of specimens were measured by a laser profiler. A laser texture scanner and a circular texture meter were also used to calculate the MPD of sample surfaces. Three-dimensional rendering of the surfaces were obtained from laser texture scanner and x-ray CT scans. Using the experimental data collected in this study, relationships between friction resistance and macrotexture obtained from different methods were investigated. The estimated texture depths predicted from laser profiler, laser texture scanner, and CT meter were comparable to the MTD obtained from sand patch tests. Also, the friction resistance increased with increasing surface macrotexture.
\end{abstract}

Keywords: macrotexture; dynamic friction test; mean profile depth; mean texture depth; pavement materials; sand patch test.

Reference to this paper should be made as follows: Sezen, H.; Fisco, N. 2013. Evaluation and comparison of surface macrotexture and friction measurement methods, Journal of Civil Engineering and Management 19(3): 387-399.

\section{Introduction}

It is estimated that a large percentage of roadway accidents are related to inadequate or poor pavement conditions. Based on historical data, it has been reported that a significantly large number of crashes occur under wet pavement conditions (Dahir, Grambling 1990). Therefore, it is crucial to investigate and understand the factors contributing to roadway accidents. Specifically, investigation of potential relationships between quantifiable pavement surface characteristics, such as friction and texture, and wet accident locations will help better understand and mitigate the problem.

One of the main parameters used to quantify these characteristics is macrotexture. Macrotexture can be defined as surface irregularities of wavelength varying between approximately 0.5 and $50 \mathrm{~mm}$. Macrotexture plays a crucial role in preventing hydroplaning by providing drainage channels that expel water from between tire and pavement (Snyder 2007). It has been found to be a very good indicator of wet and dry pavement friction, having a similar level to correlation to skid tire tests. The surface texture is related to and may be used in determination of noise emission, friction, rolling resistance, splash and spray, and tire wear which all contribute to the design and performance of a roadway.

The sand patch method (ASTM E965 2006) has been historically used as the main technique for measuring pavement macrotexture. The texture depth of the surface on which the sand patch test is performed, is represented by the mean texture depth (MTD). Recently developed laser-based systems allows for direct measurement of macrotexture, not only statically, but also at different speeds. In this research, several methods were used to determine texture characteristics of laboratory specimens with different surface characteristics. Results from sand patch tests, computed tomography (CT) scanning, laser profile 
scanning, laser texture scanning, and circular texture meter scanning were evaluated and compared.

The use of digital imagery, especially computed tomography (CT) scans, to measure three-dimensional surface characteristics of pavements has shown much promise. Similarly, the use of digital imagery has been combined with field tests to come up with models for predicting pavement characteristics. Ergun et al. (2005) used texture parameters, obtained using noncontact methods, to predict friction coefficients of roadway surfaces. This study showed that a relation can be established between micro- and macrotexture and the friction coefficient of a pavement surface, which is also explored in this paper.

Henry et al. (2000) discuss the use of the circular texture meter (CT meter) and dynamic friction tester (DFT) in determining the international friction index (IFI) values for different pavement types. The IFI is used to harmonize friction and macrotexture measurements from different measurement devices in order to calculate a universal friction number. The mean profile depth (MPD) from CT meter and friction measurements from the DFT at $20 \mathrm{~km} / \mathrm{h}$ were used to determine the IFI value at $60 \mathrm{~km} / \mathrm{h}$ (F60) using a linear relationship. The F60 values for each pavement surface were then compared to the friction measurements obtained from the DFT at $60 \mathrm{~km} / \mathrm{h}$ to see how well they correlated. The research by Henry et al. (2000) is relevant to the current study because the same equipment (CT meter and DFT) is used to determine the IFI values for the sample surfaces, and a similar comparison was performed.

\section{ASTM standards}

During the course of this research, a few ASTM standards are referenced and utilized frequently. These selected standards are presented and summarized in this section.

ASTM E965 (2006) describes the test procedure for carrying out the sand patch test to measure the texture of a surface. Equation 1 presented in the standard for determining the MTD from test data:

$$
\mathrm{MTD}=\frac{4 \times V}{\pi \times D^{2}},
$$

where $V$ is volume of sand or glass spheres and $D$ is average diameter of the patch. This equation is used in this research to convert the measurements obtained from sand patch tests into MTD values for comparison with other measurement methods.

ASTM E1845 (2005) describes the calculation of MPD from a profile of pavement macrotexture. It states that the profile is divided, for analysis purposes, into segments with a base length of $100 \mathrm{~mm}$.
The slope of each segment is suppressed by subtracting a linear regression of the segment, which is further divided in half and the height of the highest peak is determined. The difference between the height and the average level of the segment is then calculated. The average values of these differences for all segments making up the measured profile are finally reported as the MPD for the entire pavement section. Additionally, this standard presents Eqn (2) for calculating the estimated texture depth (ETD) from MPD in mm units:

$$
\mathrm{ETD}=0.2+0.8 \times \text { MPD }
$$

Equation 2 is used here to transform the MPD measurements obtained using the laser texture scanner and laser profiler into ETD values so that they could be compared to the MTD values obtained from the sand patch tests.

ASTM E1911 (2009) outlines the process of measuring surface frictional properties of surfaces as a function of speed using the DFT. ASTM E1911 states that the DFT friction coefficients for speeds of $12,24,36$, and $48 \mathrm{mph}(20,40,60$, and $80 \mathrm{~km} / \mathrm{h})$ need to be measured and used in the analysis.

ASTM E1960 (2007) describes the calculation of the IFI from macrotexture and wet pavement friction measurements. The IFI is used to harmonize friction and macrotexture measurements from different measurement devices in order to calculate a universal friction number. ASTM E1960 outlines the calculation in two main steps. First, the friction value at slip speed $S$ is adjusted to $60 \mathrm{~km} / \mathrm{h}$ using Eqn (3):

$$
\left.\mathrm{FR} 60=\mathrm{FRS} \times \exp \left[(\mathrm{S}-60) / \mathrm{S}_{\mathrm{p}}\right)\right]
$$

where $S_{p}$ is speed constant $(=14.2+89.7 \cdot \mathrm{MPD}$, where MPD is in $\mathrm{mm}), S$ is slip speed $(\mathrm{km} / \mathrm{h})$, FRS is friction measured at slip speed $S$, and FR60 is the adjusted value of friction at slip speed $S$. Then, the calibrated friction number F60 is calculated using Eqn (4):

$$
\mathrm{F} 60=\mathrm{A}+\mathrm{B} \times \mathrm{FR} 60,
$$

where $A$ and $B$ are constants specific to the dynamic friction measurement device being used. In the case of the DFT, which was used in this study (Fig. 1e and f), ASTM E1960 specifies the values for $A$ and $B$ as 0.081 and 0.732 , respectively. This method of calculating the IFI is used in this study to transform the measurements obtained from the CT meter and DFT into normalized friction values.

ASTM E2157 (2005) presents the method for obtaining macrotexture profiles using a circular track meter, otherwise known as a circular texture (CT) meter (Fig. 1c). It describes the measurement device and how the $11.2 \mathrm{in}$. diameter $(284 \mathrm{~mm})$ track is split 


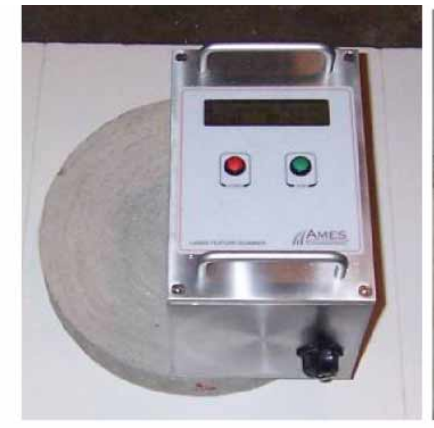

a)

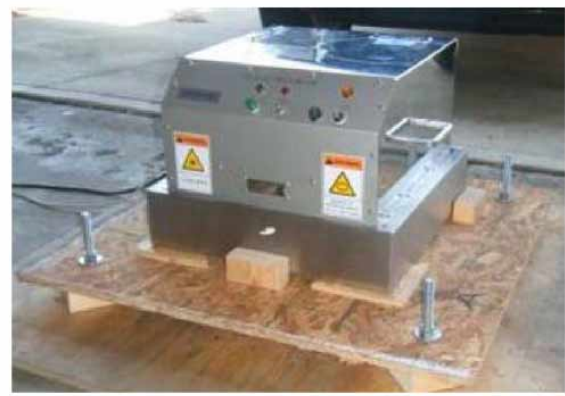

c)

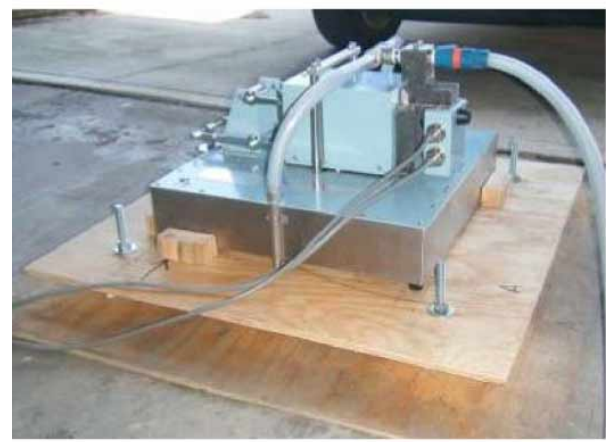

e)

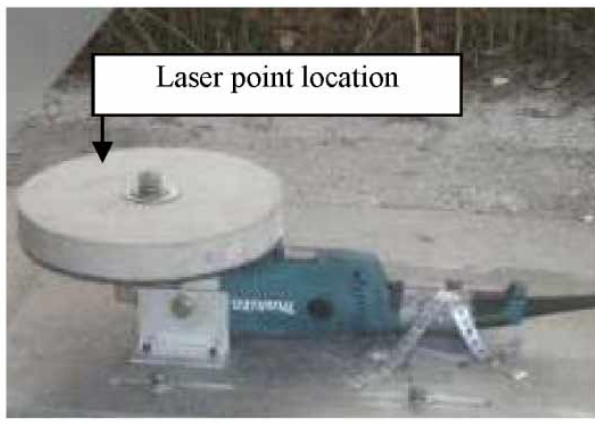

b)

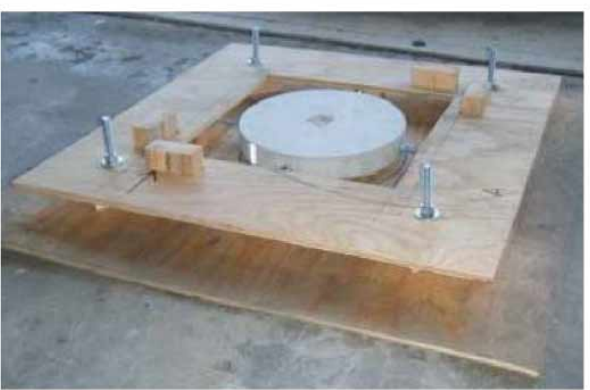

d)

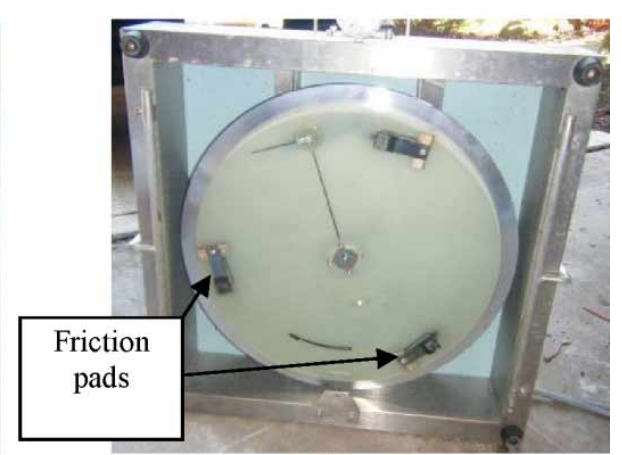

f)

Fig. 1. Testing apparatus: (a) laser texture scanner; (b) apparatus for Dynatest laser scanner and sample; (c) CT meter on test rig; (d) adjustable test rig for CT meter and DFT; (e) DFT on test rig; (f) bottom of DFT showing friction pads

into eight arcs of equal length, with the MPD being calculated for each arc. Additionally, the standard provides Eqn (5) to convert the MPD measured by the CT meter into MTD in mm units:

$$
\mathrm{MTD}=0.947 \times \mathrm{MPD}+0.069 .
$$

To avoid confusion during analysis of different methods, the MTD in this equation is referred to as ETD throughout this paper.

\section{Sample properties}

Asphalt and Portland cement concrete and various other samples with varying textured surfaces and mix designs were constructed or obtained (Fig. 2). Detailed description of each sample and material properties can be found in Fisco (2009). Three different asphalt samples with an approximately $356 \mathrm{~mm}$ diameter and $76 \mathrm{~mm}$ thickness were created by manually compressing the asphalt material using a hand tamp in a metal mold (Fig. 2g). Asphalt materials were prepared by a local pavement construction company and the materials were compacted in the molds to best represent the field conditions for each asphalt sample. Stone matrix asphalt (SMA, medium grade) sample had a relatively rough surface texture but less than that of the coarse-graded asphalt. Sample was somewhat porous with uniformly distributed small voids. Coarse-graded asphalt concrete or open-graded sample had large surface irregularities. Sample appeared very porous and had a very rough surface texture. Dense-graded asphalt sample had minimal voids between aggregates and binder with a relatively coarse surface texture. It had the smoothest surface of the three asphalt types used in this research. 


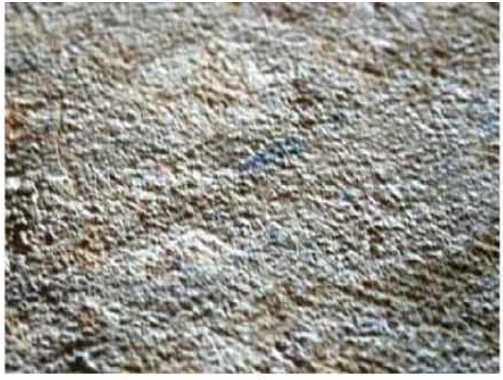

a)

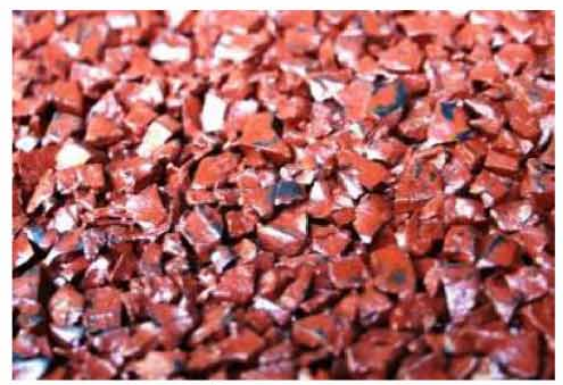

d)

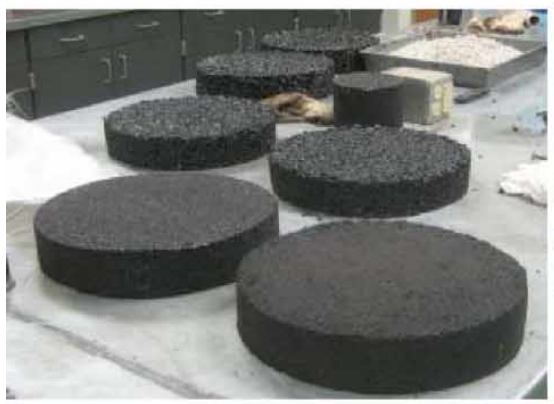

g)

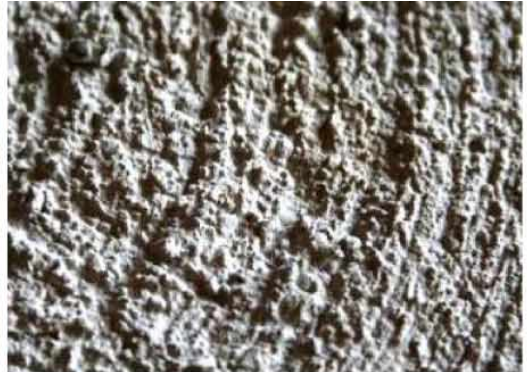

b)

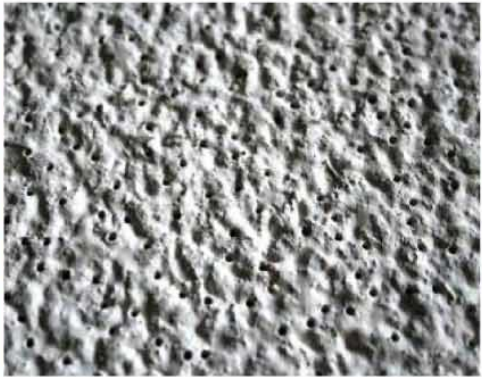

e)

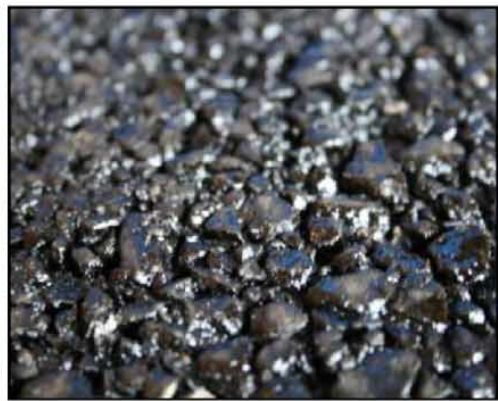

h)

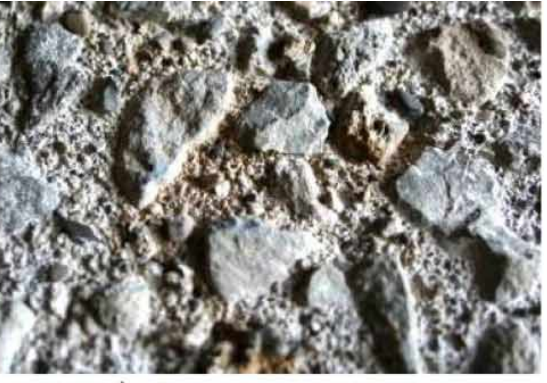

c)

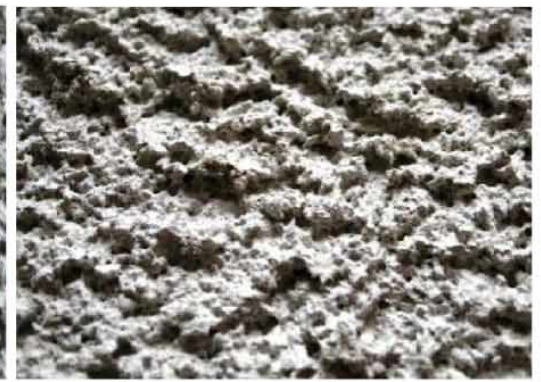

f)

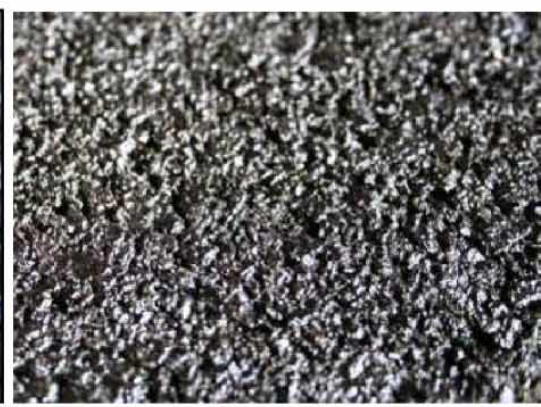

i)

Fig. 2. Selected samples and surface texture: (a) burlap layover Portland cement concrete; (b) burlap drag concrete; (c) exposed aggregate concrete; (d) rubber stepping stone; (e) Alpine panel; (f) Cheyenne tile; (g) 356 mm diameter asphalt samples; (h) SMA asphalt; (i) dense graded asphalt sample

Concrete samples were $305 \mathrm{~mm}$ in diameter and $38 \mathrm{~mm}$ thick. Samples placed in circular cardboard molds were hand finished to create different types of finishes. The finish was done in a radial or circular pattern to mimic a straight pattern as the samples spin. Two samples of each finish, except for burlap layover, were made for consistency. The burlap layover concrete specimens were created by placing a piece of moistened coarse burlap (AASHTO M182 Class 2) on top of sample surface for 24 hours and then removed. Texture of random thatched burlap left a pattern on sample surface (Fig. 2a). Burlap drag specimens were prepared by dragging a moistened piece of coarse burlap (AASHTO M182 Class 2) along surface, creating $1.6 \mathrm{~mm}$ deep striations (Fig. 2b). Artificial turf drag was prepared using an inverted piece of artificial turf with $6.4 \mathrm{~mm}$ long blades and 9000 blades per $\mathrm{ft}^{2}$ dragged along the surface to create striations. Longitudinal broom specimens were created using a hand broom with hair bristles dragged along surface, creating 1.6-3.2 $\mathrm{mm}$ deep striations.
Transverse tine samples had 3.2-6.4 mm deep, $3.2 \mathrm{~mm}$ wide grooves spaced at $19 \mathrm{~mm}$ at a radius of $127 \mathrm{~mm}$, which were created using a metal trowel. Surface of "smooth finish" concrete samples was made as smooth as possible using a metal trowel. A retarder (Master Builders Technologies Masterpave water-reducing and retarding admixture) was sprayed onto the surface of the exposed aggregate samples and concrete was left to set for five hours. Water was subsequently sprayed onto the surface and the top mortar was removed leaving the top layer or aggregate exposed. Compressed air was then sprayed onto surface to blow away any remaining loose fines.

Rubber stepping stone sample was a round, discshaped artificial stepping-stone made of recycled rubber pellets. The disc was $330 \mathrm{~mm}$ in diameter, $32 \mathrm{~mm}$ thick, and was very porous. Because of its porosity and appearance, this sample was very similar to porous concrete. The surface of the disc was moderately coarse due to the jagged rubber pellets (Fig. 2d). Tivoli ceiling tile sample was a wood fiber 
ceiling panel and had smooth surface with random $1 \mathrm{~mm}$ deep indentations for aesthetics. Cheyenne ceiling panel sample was a ceiling panel that was made of slag wool and various minerals. Texture of the tile was very rough with numerous sharp peaks and had many irregularities. Sandpaper discs of grit 50, 60, and 80 were also used. Aluminum oxide grains, held on by adhesive, give the paper its rough texture. The 50 -grit sandpaper is coarser than the 60 grit, which is much coarser than the 80 grit. Granite stepping-stone sample had two distinct surfaces. One was polished and very smooth while the other was relatively rough from where the piece was cut but not finished.

\section{Macrotexture measurement methods}

Sand patch method or volumetric patch method involves spreading of fine material in a patch over a test surface. A fixed volume of sand or glass spheres is poured on a test location. Using a disk, the sample is spread out in a circular motion while trying to keep the sand or glass spheres evenly distributed until the disk comes in contact with the material surface. The average diameter of the four circular patches created on a surface is used to calculate the average patch area. By dividing the volume of material by the calculated patch area, the average depth of the layer or MTD of the surface is calculated. Figure 3a shows four sand patch tests performed on an exposed Portland cement concrete sample using $12.5 \mathrm{~mL}$ of fine sand for each test.

CT scanning is typically a medical imaging technique, which combines two-dimensional $\mathrm{x}$-rays or "slices" to make a three-dimensional image of the object being scanned around a single axis of rotation. The specimen placed on a bed moves through a gantry, or opening, of the machine. As the specimen passes through, the gantry rotates around the bed and specimen (single axis of rotation) and takes twodimensional $\mathrm{x}$-ray images of the specimen. In this research, two-dimensional images and three-dimensional (3-D) rendering of selected samples were produced using a Siemens SOMATOM Sensation CT scanner and TeraRecon Aquarius imaging software. Figure $3 \mathrm{c}$ and $\mathrm{d}$ show the scanned exposed aggregate sample surface and 3-D rendering of $100 \mathrm{~mm}$ square area. Use of CT imaging was limited in this study; however it showed great promise in obtaining accurate representations of the sample surface, profile and internal structure.

In recent years, different laser tools have been successfully used to measure the surface macrotexture of highway pavements (Sezen et al. 2008). In this project, a laser profiler provided by Dynatest (Selcom Optocator 2008-180/390) was used to measure and evaluate the macrotexture of test samples. The laser was housed in a steel box that was approximately $305 \mathrm{~mm}$ above a specially fabricated apparatus
(Fig. 1b). The apparatus was built to spin the samples to simulate the Dynatest laser profiler driving over the surface of the sample. A Makita 7500 RPM metal grinder was attached to an aluminum plate, which was in turn bolted to a concrete slab using lag bolts and slots cut in the plate (Fig. 1b). The slots were used to vary the diameter at which the sample was being tested. Samples were bolted to the aluminum plate and grinder. To make all tests comparable, readings were taken on each spinning sample for a total of $152 \mathrm{~m}$. Over this distance, the MPD was sampled every $25 \mathrm{~mm}$ and an average of all MPDs over the $152 \mathrm{~m}$ section was used as the average MPD for that set diameter at 152, 230 or $280 \mathrm{~mm}$ (Fig. 4).

The laser texture scanner system produced by Ames Engineering is used to measure macrotexture of the sample surfaces. The scanner is a standalone unit (Fig. 1a) and scans the material surface in multiple line scans to render a 3-D image of the surface. The scanner is capable of scanning an area that is $102 \mathrm{~mm}$ long and $76 \mathrm{~mm}$ wide and has a maximum capacity of 1200 lines, which equates to an average spacing of $0.0635 \mathrm{~mm}$ between scan lines. Four different quarters were tested on each sample (Fig. 4). In addition to measurement of MPD values, a 3-D image of the sample surface was rendered by the texture scanner. $3-\mathrm{D}$ rendering of the exposed aggregate concrete sample is shown in Figure 3b.

Circular texture meter (CT meter) uses a laser to measure the MPD of a surface along a circular track with a fixed diameter of $284 \mathrm{~mm}$. The device used in this study was the Nippo CTM manufactured by the Nippo Sangyo Co. of Japan. The sample is split radially into eight $112 \mathrm{~mm}$ arcs of equal length (labeled A through $\mathrm{H}$ ). The MPD of each arc is averaged to give an overall MPD for the entire surface and produce a 2-D surface profile. All specimens described above were placed on the ground or in a testing rig and the CT meter was placed above each specimen (Figure 1c). Surface of each specimen was scanned three times along the same $284 \mathrm{~mm}$ diameter circular track, with an MPD reading and a 2-D surface profile being recorded for each test. As an example, the measured surface profile of the exposed aggregate sample is shown in Figure 3e.

DFT is a device that measures the frictional properties of wet surfaces. It consists of a spinning disk with three spring-loaded rubber pads mounted on it that contact the testing surface and generate friction and a torque, which causes the disk to lose velocity (Fig. 1e and f). The torque generated by the friction between the pads and the testing surface is measured and used to determine the friction coefficient as a function of slip speed. A water supply is used to saturate the testing surface, but is turned off once the pads make contact with the surface. The device used in this study, Nippo DFT, was manufactured by the 


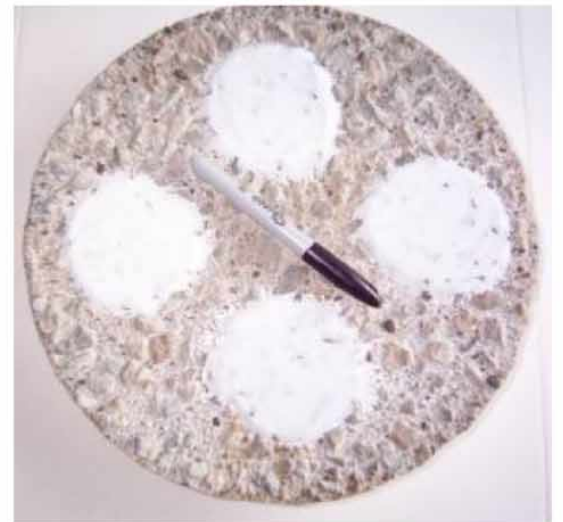

a)

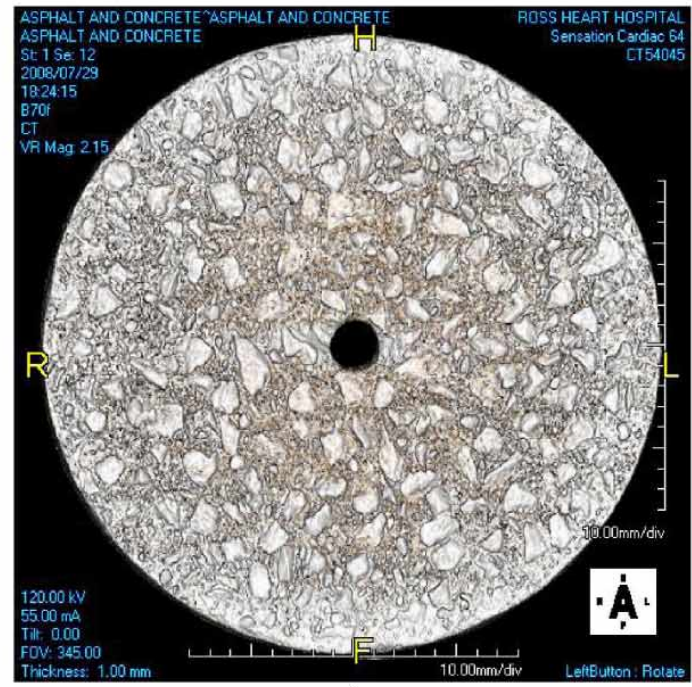

c)

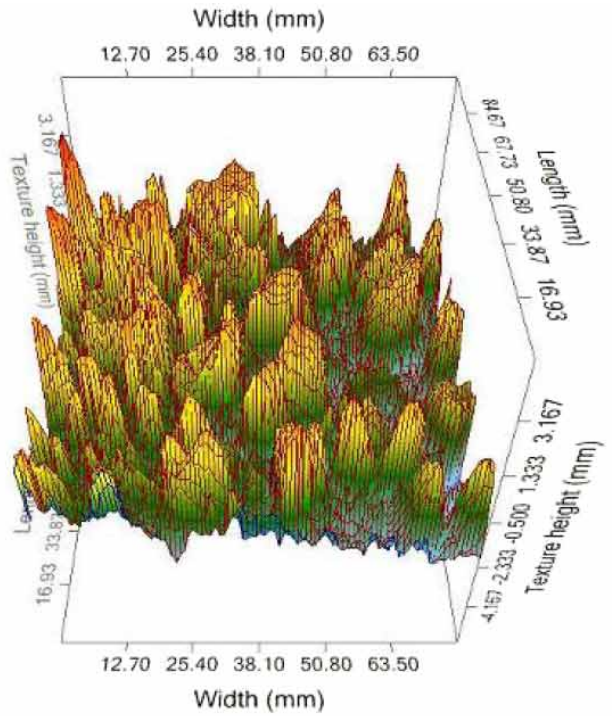

b)

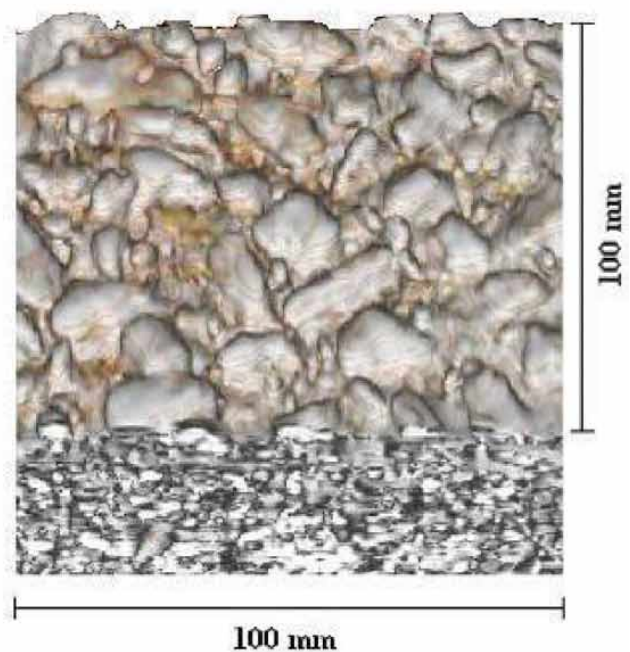

d)

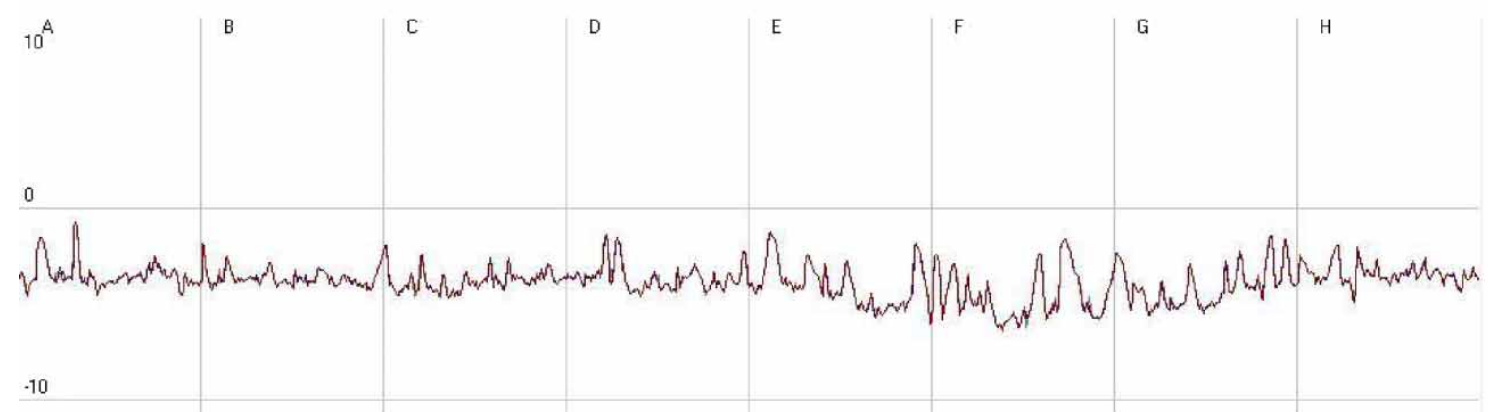

e)

Fig. 3. Procedures and results for an exposed aggregate concrete sample from: (a) sand patch test; (b) laser texture scanner; (c) and (d) x-ray CT scanning; (e) CT meter surface profiling (in $\mathrm{mm}$ )

Nippo Sangyo Co. of Tokyo, Japan. It has a maximum testing speed of $100 \mathrm{~km} / \mathrm{h}$ and the $16 \mathrm{~mm}$ wide rubber pads (Fig. 1f) are set on a diameter of $305 \mathrm{~mm}$. The DFT requires an external power supply (which was supplied by a car battery during testing), a controller, and a personal computer to store the data.
Each sample was tested at least three times along the same $305 \mathrm{~mm}$ diameter, with the friction coefficient as a function of slip speed being recorded. Only the Portland cement concrete, asphalt, and rubber stepping-stone samples were tested using the DFT. The sandpaper and ceiling tile samples were not tested 


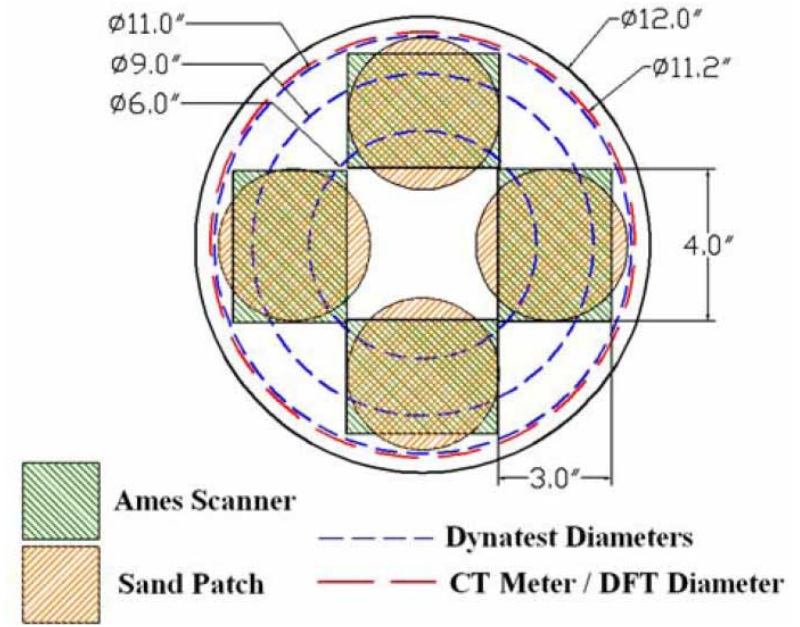

Fig. 4. Summary of areas or paths tested on each sample

because the addition of water to these paper-based samples would destroy them and give inaccurate measurements during testing. Samples were tested using a test rig, which consisted of two wooden platforms as shown in Figure 1d. The bottom platform was fixed and held the sample in place using four bolts, while the top platform was adjustable in order to accommodate samples of different thicknesses. The test rig prevented the movement of the DFT and specimens during testing. The maximum speed used during testing was $80 \mathrm{~km} / \mathrm{h}$, as per ASTM E1911 designation (2009). During testing, the pads were changed after every four different sample tests, due to wearing of the pads that occurred during testing (Fig. 1f).

\section{Comparison of surface macrotexture methods}

The Dynatest laser profiler measures texture by obtaining MPD readings for a 2-D profile of the surface in the direction of travel. These MPD values were transformed into ETD (Eqn (2)) so that they can be compared to MTD measurements from the sand patch method. The Ames laser scanner is a 3-D laserbased method that produces a $3-D$ profile of a $102 \times$ $76 \mathrm{~mm}$ area by making repeated passes with the laser and compiling the 2-D profile data for each pass. From these compiled profiles, ETD values are calculated (Eqn (2)) and are compared with the MTD values as recommended by the ASTM E965 (2006) and ASTM E1845 (2005).

The CT meter is another laser-based method to measure 2-D texture and MPD along a circular track. These MPD values are also transformed into MTD using Eqn (5) per ASTM E2157 (2005) so that they can be compared to measurements from the sand patch tests and other methods. For the purpose of this study, this MTD will be referred to as ETD, as to avoid confusion when the sample macrotextures from different methods are compared below. A disadvantage of this method is that it only measures texture along a single 2-D profile and, therefore, may not characterize the other parts of the surface being tested, which may be rougher or smoother than the track being measured. These features of the surface texture that are missed by the CT meter can be captured using the 3-D texture measurement methods such as the sand patch and laser scanner. The main disadvantage of 2-D circular CT meter and 3-D laser scanner is their limitation on the size of scanned area. They are not practical to measure the macrotexture of large pavement segments. 2-D Dynatest laser profiler can be handy to measure the macrotexture of large surfaces such as highways.

One problem with 2-D testing concerns porous, open-graded, and highly textured surfaces. Because these surfaces have large voids, it is very unlikely that the 2-D profile will capture all the highest peaks and the lowest valleys of the voids. Rather, the profile captures some of the extremes but, for the most part, captures points in between, thus underestimating the actual texture. Similarly, sand patch tests cannot accurately predict the texture of very rough or porous surfaces because even distribution of sand or glass spheres may not be possible.

\subsection{Comparison of macrotexture data}

MTD values from volumetric sand patch tests are reported in Table 1 along with the ETD values calculated from Eqns (2) and (5) using the MPD values from the Ames laser texture scanner, Dynatest laser profiler, and CT meter tests. Data reported in Table 1 for the laser profiler corresponds to a laser speed of $40 \mathrm{~km} / \mathrm{h}$. Table 1 shows that the samples with the highest MTD and ETD values are open-graded and SMA asphalt samples, and exposed aggregate concrete samples. Conversely, the smooth granite samples had the smallest average MPD and ETD values. Of the concrete samples, the exposed aggregate samples were the roughest, while the smooth finished samples had the smallest MPD and ETD values. For the sandpaper samples, the average MPD and ETD decreased as grit number increased, which is expected, since the fineness of sandpaper increases as the grit number increases.

Table 1 shows that, in general, the laser texture scanner results compare only slightly better with the sand patch MTD than the results from Dynatest laser profiler and CT meter ETD. The average percent difference between the sand patch data (MTD) and other methods (ETD) was calculated. When the average was taken, the porous samples (e.g. rubber stepping-stone and open-graded asphalt) were not taken into account due to the potential inadequacy of the sand patch method on those surface types. As mentioned above, when the sand is poured onto the 
Table 1. Average MTD from sand patch tests compared with average ETD for laser texture scanner, Dynatest laser profiler at $25 \mathrm{mph}$ speed, and CT meter

\begin{tabular}{|c|c|c|c|c|}
\hline & Sand patch & Laser scanner & Laser profiler & CT meter \\
\hline & MTD (mm) & ETD (mm) & ETD (mm) & $\operatorname{ETD}(\mathrm{mm})$ \\
\hline 50 Grit sandpaper & 0.305 & 0.389 & 0.505 & 0.224 \\
\hline 60 Grit sandpaper & 0.337 & 0.345 & 0.430 & 0.198 \\
\hline 80 Grit sandpaper & 0.237 & 0.345 & 0.484 & 0.154 \\
\hline Alpine tile & 0.708 & 0.677 & 0.708 & 0.584 \\
\hline Broom 1 & 1.372 & 1.103 & 0.776 & 0.685 \\
\hline Broom 2 & 1.324 & 1.043 & 0.810 & 0.656 \\
\hline Burlap drag 1 & 0.767 & 0.787 & 0.654 & 0.748 \\
\hline Burlap drag 2 & 0.738 & 0.845 & 0.688 & 0.795 \\
\hline Burlap layover & 0.354 & 0.465 & - & 0.423 \\
\hline Cheyenne tile & 2.498 & 1.878 & 2.334 & - \\
\hline Dense graded asphalt & 0.703 & 0.636 & 2.532 & 1.382 \\
\hline Exposed aggregate 1 & 2.492 & 1.869 & 1.934 & 1.966 \\
\hline Exposed aggregate 2 & 2.486 & 1.836 & 1.954 & 1.714 \\
\hline Open graded asphalt 1 & 7.885 & 2.682 & - & 3.229 \\
\hline Open graded asphalt 2 & 11.85 & 2.276 & - & 5.508 \\
\hline Radial tine 1 & 2.206 & 1.790 & 1.948 & 1.101 \\
\hline Radial tine 2 & 2.187 & 1.761 & 2.286 & 0.814 \\
\hline Rough granite & 0.364 & 0.608 & 0.606 & 0.479 \\
\hline Rubber stepping stone & 3.259 & 1.049 & 2.936 & 0.959 \\
\hline SMA & 2.864 & 1.582 & 3.223 & 1.654 \\
\hline Smooth 1 & 1.855 & 1.296 & 2.222 & 0.322 \\
\hline Smooth 2 & 0.166 & 0.324 & 0.329 & 0.236 \\
\hline Smooth granite & 0.223 & 0.327 & 0.349 & 0.104 \\
\hline Tivoli panel (12") & 0.130 & 0.265 & 0.403 & 0.249 \\
\hline Turf drag 1 & 0.234 & 0.341 & 0.417 & 0.536 \\
\hline Turf drag 2 & 1.131 & 1.008 & 0.728 & 0.959 \\
\hline
\end{tabular}

porous surface, the sand flows in the voids that are present throughout the material, giving a much smaller value for the MTD and, therefore, overestimating it. This is one advantage of using a laser based system. Also, the asphalt samples were not taken into account for the Dynatest laser profiler comparisons. This was done because of the problem of changing of surface texture while the samples were spun at high speeds and could not be adequately restrained. The overall average percent difference between sand patch MTD and ETD from the Ames laser texture scanner, Dynatest laser profiler and CT meter was $28 \%, 36 \%$ and $37 \%$, respectively.

The percent differences were averaged and classified according to type of sample and texture (overly rough with MTD more than $1.90 \mathrm{~mm}$ or overly smooth with MTD less than $0.25 \mathrm{~mm}$ ). It was found that the laser texture scanner had the smallest percent difference for the concrete surface breakdown, while the CT meter had the least percent difference for smoother surfaces. The laser profiler had the smallest percent difference for the overly rough category.

For porous samples, a realistic comparison could not be done due to the inadequacy of the sand patch test and due to the centripetal separation problems occurring with the laboratory testing of some asphalt samples using laser profiler at high speed. Assuming that the laser scanner gives a relatively accurate measure of ETD, which seems to be the case in our analysis, for porous samples the sand patch test overestimates the actual texture of the surface.

\subsection{Dynamic friction tests}

A friction coefficient as a function of slip speed was obtained for every speed from 0 to $80 \mathrm{~km} / \mathrm{h}$, however, only the coefficients at $20,40,60$, and $80 \mathrm{~km} / \mathrm{h}$ were used for analysis, as recommended by ASTM E1911 (2009). For each speed, the average of the three (or more) coefficients measured at that speed for each sample was taken. In Table 2, the average friction coefficients at these speeds for each sample are reported. Table 2 shows that the coefficients of friction, for the most part, decrease as slip speed increases. The exceptions are exposed aggregate 1, tine 1 , and both turf drag samples, which exhibit an increase in friction coefficient at $60 \mathrm{~km} / \mathrm{h}$. It can also be seen that there is considerable variability between some samples of the same type. An example of this is the difference between measured friction coefficients of the SMA samples, which vary at $20 \mathrm{~km} / \mathrm{h}$ by 0.679 and by 0.466 at $60 \mathrm{~km} / \mathrm{h}$. Another interesting result is that the samples with the highest friction coefficient at 
Table 2. Measured friction coefficients as a function of speed and calculated IFI values

\begin{tabular}{|c|c|c|c|c|c|c|c|}
\hline \multirow[b]{2}{*}{ Sample } & \multicolumn{4}{|c|}{ Friction coefficients for speeds in $\mathrm{km} / \mathrm{h}$} & \multirow[b]{2}{*}{ CT meter MPD (mm) } & \multirow[b]{2}{*}{ FR60 } & \multirow[b]{2}{*}{ F60 } \\
\hline & 20 & 40 & 60 & 80 & & & \\
\hline Broom 1 & 0.477 & 0.465 & 0.456 & 0.226 & 0.65 & 0.208 & 0.23 \\
\hline Broom 2 & 0.500 & 0.456 & 0.461 & 0.222 & 0.62 & 0.212 & 0.24 \\
\hline Burlap drag 1 & 0.383 & 0.365 & 0.340 & 0.207 & 0.72 & 0.178 & 0.21 \\
\hline Burlap drag 2 & 0.433 & 0.418 & 0.408 & 0.210 & 0.77 & 0.210 & 0.23 \\
\hline Burlap layover & 0.636 & 0.509 & 0.339 & 0.178 & 0.37 & 0.181 & 0.21 \\
\hline Dense graded asphalt & 0.426 & 0.360 & 0.355 & 0.263 & 1.39 & 0.276 & 0.28 \\
\hline Exposed aggregate 1 & 0.525 & 0.608 & 0.633 & 0.205 & 2.00 & 0.385 & 0.36 \\
\hline Exposed aggregate 2 & 0.604 & 0.630 & 0.621 & 0.225 & 1.74 & 0.425 & 0.39 \\
\hline Open graded asphalt 1 & 0.951 & 0.714 & 0.565 & 0.245 & 3.34 & 0.785 & 0.66 \\
\hline Open graded asphalt 2 & 0.930 & 0.810 & 0.698 & 0.217 & 5.74 & 0.830 & 0.69 \\
\hline Rubber stepping stone & 1.092 & 0.878 & 0.540 & 0.217 & 0.94 & 0.594 & 0.52 \\
\hline SMA 1 & 0.958 & 0.838 & 0.731 & 0.237 & 1.67 & 0.665 & 0.57 \\
\hline SMA 2 & 0.279 & 0.263 & 0.265 & 0.177 & 1.54 & 0.188 & 0.22 \\
\hline Smooth 1 & 0.331 & 0.306 & 0.291 & 0.172 & 0.27 & 0.069 & 0.13 \\
\hline Smooth 2 & 0.246 & 0.224 & 0.203 & 0.120 & 0.18 & 0.033 & 0.11 \\
\hline Tine 1 & 0.567 & 0.560 & 0.596 & 0.222 & 1.09 & 0.332 & 0.32 \\
\hline Tine 2 & 0.576 & 0.543 & 0.535 & 0.238 & 0.79 & 0.284 & 0.29 \\
\hline Turf drag 1 & 0.450 & 0.433 & 0.440 & 0.227 & 0.49 & 0.161 & 0.20 \\
\hline Turf drag 2 & 0.510 & 0.494 & 0.500 & 0.232 & 0.94 & 0.277 & 0.28 \\
\hline
\end{tabular}

$20 \mathrm{~km} / \mathrm{h}$, which were the rubber stepping stone (1.092) and SMA 1 (0.958), do not have the highest coefficient at the higher speeds of 60 and $80 \mathrm{~km} / \mathrm{h}$.

A further point of interest is that as speed increases, the difference in friction coefficients between different surface types gets smaller. At $20 \mathrm{~km} / \mathrm{h}$ the coefficients have a range of 0.847 , while at 40 and $60 \mathrm{~km} / \mathrm{h}$ the ranges of values are 0.654 and 0.527 , respectively. At $80 \mathrm{~km} / \mathrm{h}$ the range in friction coefficients is only 0.143 , meaning that at high speeds surface type does not have a great influence on friction coefficient. In addition to obtaining the friction coefficients as a function of slip speed for each sample, a graph of the friction coefficient versus slip speed was obtained using the DFT analysis package developed by Nippo Sangyo Co. Examples of these plots are provided in Figure 5.

Figure 5 shows that the coefficients of friction were relatively constant between speeds of 20 and $60 \mathrm{~km} / \mathrm{h}$. This trend was common in almost all samples, with most of the samples' coefficients of friction decreasing slightly with increasing speed during this range. All samples experienced significant drops in friction coefficient between 70 and $80 \mathrm{~km} / \mathrm{h}$. All friction tests were conducted at room temperature, at approximately 21 Celsius degrees. As a result, the effect of variation of temperature on the friction measurements is not investigated in this study.

\section{Analysis of test results}

The results from each method were analyzed by comparing the MPD data from each method with MTD values from the sand patch tests. A best-fit line and coefficient of correlation were calculated for the two methods. The closer the coefficient of correlation is to 1.0 , the better the correlation, and the more accurate the method is (Moore et al. 2009). Many other researchers (Prowell, Hanson 2005; Meegoda et al. 2005) have used this technique to compare macrotexture measuring methods, such as the CT meter and other laser profilers. The relations between MTD and MPD were found to differ from the equations presented in ASTM E1845 (2005) and ASTME 2157 (2005). A general linear relationship was obtained between sand patch MTD data and the MPD data from the laser texture scanner, laser profiler and CT meter (Fisco 2009). The general equation below (in $\mathrm{mm}$ ) is recommended to predict standard macrotexture (MTD) from MPD measured by a scanner or laser equipment:

$$
\mathrm{MTD}=1.1 \cdot \mathrm{MPD}+0.0076
$$

Friction coefficients obtained from the dynamic friction tester were compared with the ETD calculated using measurements from the CT meter. The ETD from the CT meter was used instead of that from the sand patch, laser profile or laser texture scanning methods because the CT meter measured the macrotexture along the same path that the DFT measured friction (Fig. 4).

Figure 6 shows a graphical comparison of the CT meter ETD versus friction coefficients for slip speeds of $20,40,60$, and $80 \mathrm{~km} / \mathrm{h}$. At lower speeds the friction coefficients vary greatly with ETD, where friction coefficients are always larger than 0.20 and mostly above 0.40 . This means that surface type and texture 

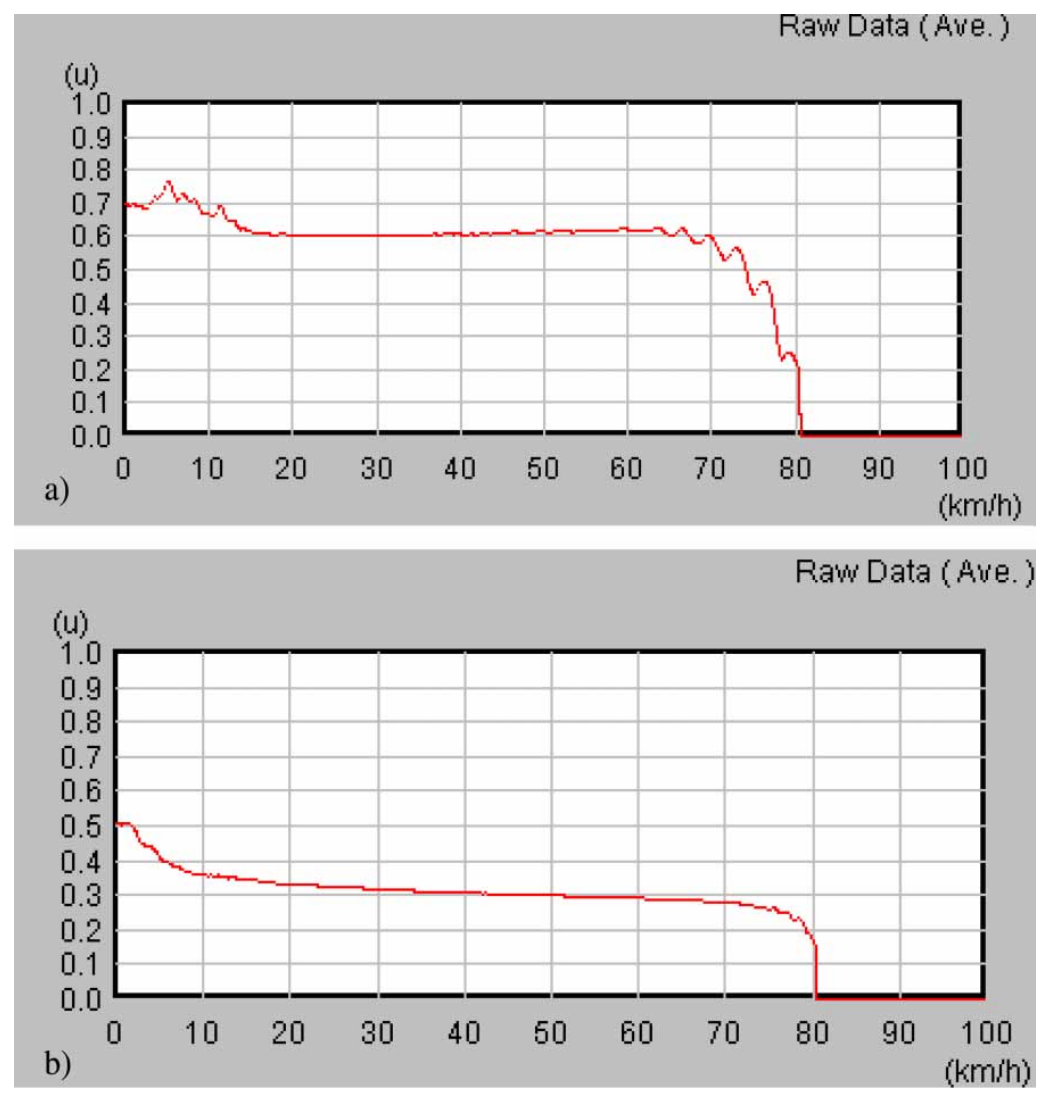

Fig. 5. Measured friction coefficient versus slip speed for samples: (a) exposed aggregate concrete 1; (b) smooth concrete 1

have a bearing on level of friction and should be taken into account when designing urban roads where the typical travel speed is within this range. Conversely, at a speed of $80 \mathrm{~km} / \mathrm{h}$ the friction coefficients obtained using the DFT do not vary with sample ETD, with all the values centered closely around 0.20 . This may have been due to the testing method, with little friction being provided due to the presence of water when the pads first make contact at $80 \mathrm{~km} / \mathrm{h}$. As the pads continued to make contact with the specimen surface as the disc slowed down, water was expelled from the surface allowing for better contact between the pad and specimen surface. Further research is needed to make stronger conclusions about the effect of macrotexture on surface friction at higher speeds (above $80 \mathrm{~km} / \mathrm{h}$ ). Figure 6 also shows that, in general, the

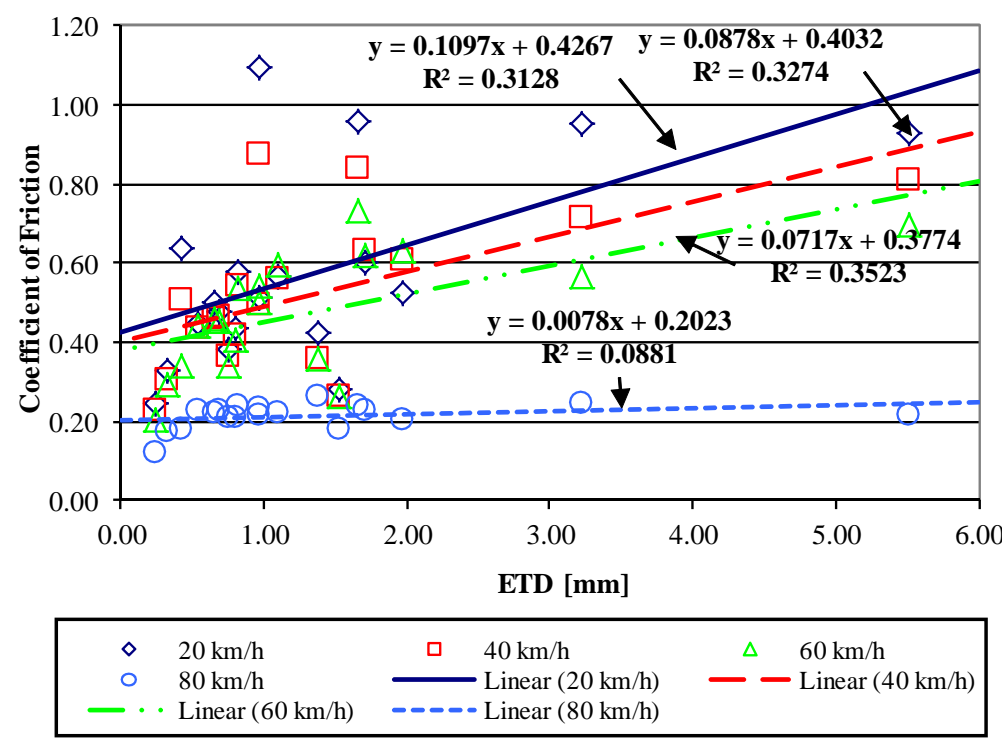

Fig. 6. CT meter ETD versus friction coefficients at varying speeds 
coefficient of friction is reduced as the speed increases, for example, from 0.70 or 0.80 at 20 to $40 \mathrm{~km} / \mathrm{h}$ to 0.20 at $80 \mathrm{~km} / \mathrm{h}$. However, the loss of friction resistance is not linear under increasing speeds as confirmed by the data presented in Table 2 and Figure 5.

\section{International friction index calculations}

The IFI is used to normalize friction numbers obtained from different friction and macrotexture measurement devices. Friction coefficients measured at any speed and MPD measurements can be used to calculate a universal friction number. Each IFI value is normalized to a slip speed of $60 \mathrm{~km} / \mathrm{h}$ and is designated F60. As per ASTM E1960 (2007), using Equations 3 and 4 , the IFI values for the samples tested in this study were calculated using the MPD measurements from the CT meter and the friction coefficients measured at $20 \mathrm{~km} / \mathrm{h}$. The friction coefficients at $20 \mathrm{~km} / \mathrm{h}$ were used because they are considered to be the most reliable and have been used by others in similar studies (Henry et al. 2000). Also, only a metric analysis was done because the constants and equations for calculating IFI were only supplied in metric units. The calculated IFI values, F60, are listed in Table 2.

Table 2 shows that the smooth finish concrete samples had the smallest calculated F60 values, at 0.11 and 0.13 , while the open graded asphalt samples had the highest at 0.66 and 0.69 . Most of the samples of similar finish had IFI values relatively close to each other. It is worth noting that the porous samples (open graded asphalt, rubber stepping stone, SMA 1) had the highest overall F60 values.

The calculated IFI values were then plotted against the CT meter ETD in Figure 7 to determine the relationship between the two. Figure 7 shows that, generally, as ETD increases, so does the value of the IFI. This is to be expected, because the more texture a surface has, the more friction it should be expected to have. Again, the CT meter ETD was used here because it was measured along approximately the same path as the DFT measurements. In addition, it allowed for the inclusion of the porous samples (open graded asphalt, rubber stepping stone, SMA 1), which would have been excluded if sand patch MTD was used due to the less realistic values of MTD calculated for porous samples as discussed above.

An additional analysis was done to compare the F60 values to the DFT measurements at a slip speed of $60 \mathrm{~km} / \mathrm{h}$. Figure 8 shows a graph of this comparison along with the linear relation and coefficient of correlation. As the figure shows, there is a good correlation, with an $\mathrm{R}^{2}$ value of 0.83 . The porous samples (open graded asphalt, rubber stepping stone, SMA 1) were outliers in this case with their very high F60 values (Table 2). These porous samples were not included in Figure 8. The linear relationship obtained in Figure 8 appears to predict the F60 values very well above DFT60 values of 0.5 , a point also found by Henry et al. (2000); it is also fairly accurate at lower DFT60 values. Therefore, this linear relation can be used to predict the IFI value, F60, for nonporous surfaces.

\section{Conclusions}

Volumetric sand patch test method, x-ray computer tomography (CT) scanner, laser profiler, laser texture scanner, and laser circular texture meter (CT meter) were used to measure and compare macrotexture of sample surfaces with varying friction and macrotexture characteristics. A DFT was used to measure surface friction resistance at different speeds. The

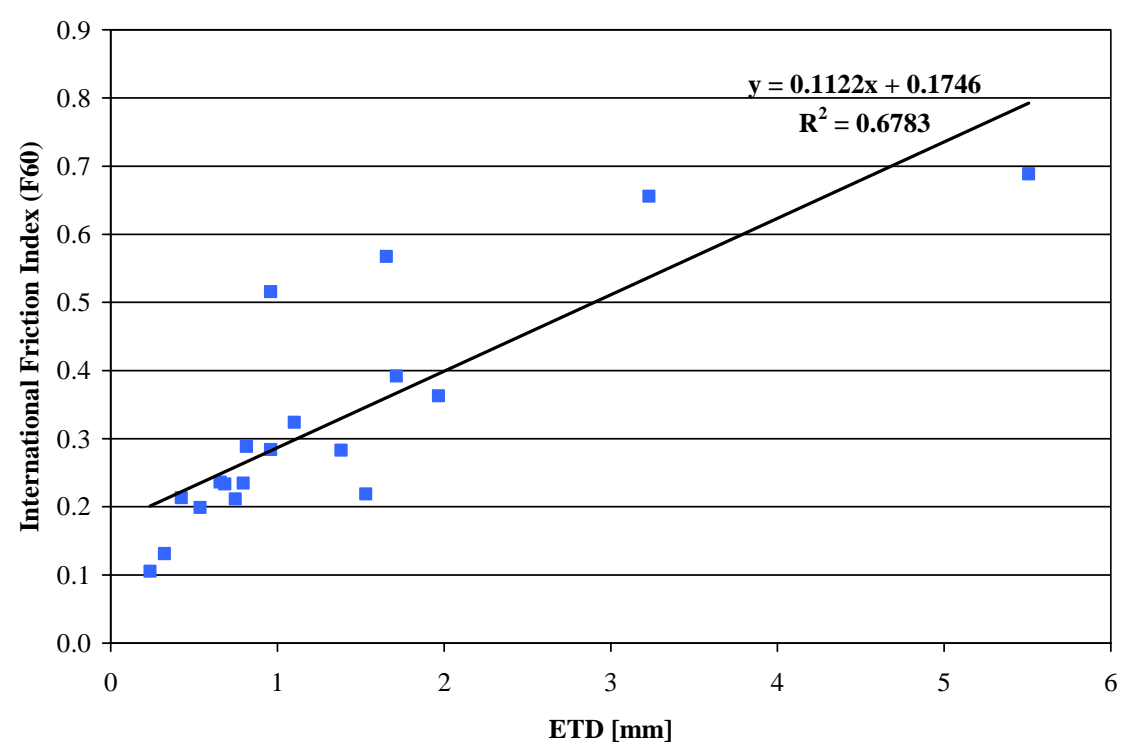

Fig. 7. CT meter ETD versus IFI 


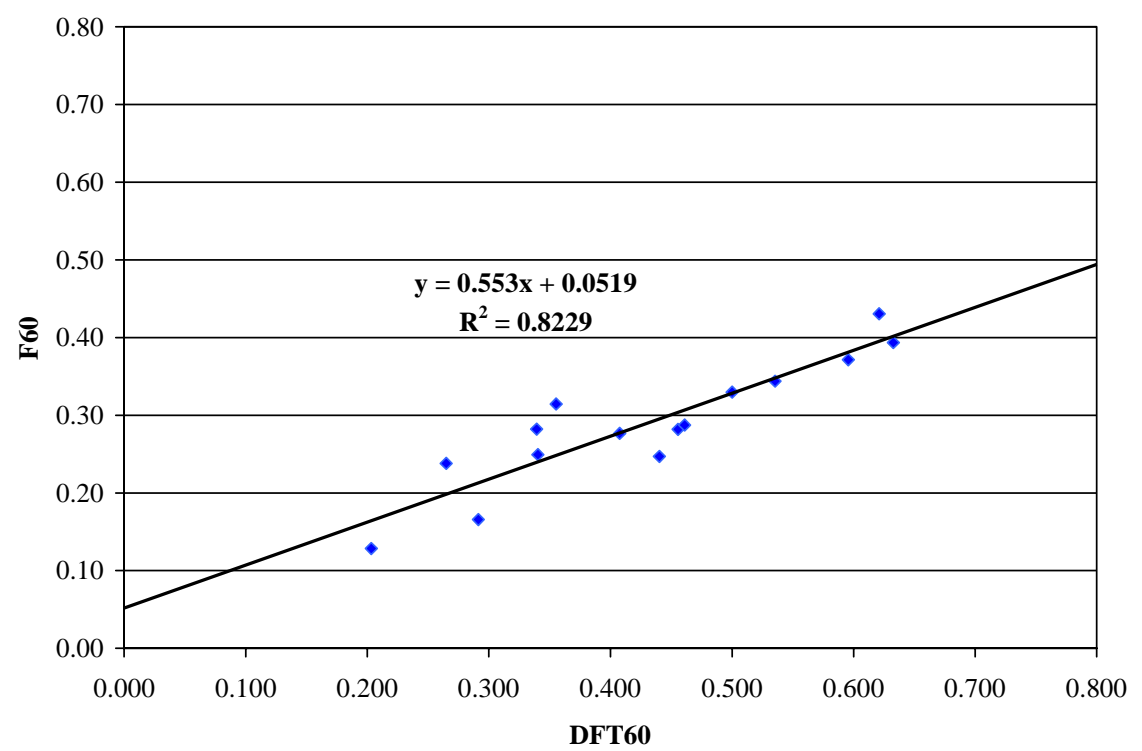

Fig. 8. F60 versus DFT measurements at $60 \mathrm{~km} / \mathrm{h}$ speed (porous samples excluded)

following conclusions were reached during this study based on evaluation of data obtained from testing of laboratory specimens:

- It is easy to apply sand patch method, which appear to predict the macrotexture of most surfaces relatively accurately. However, it was found in this research that sand patch test was inadequate for determining the macrotexture of porous samples;

- In general, the ETDs predicted from laser profiler, laser texture scanner and CT meter were comparable to the MTD obtained from sand patch tests, with an overall difference varying between 28 to $37 \%$. Macrotexture of smoother surfaces was predicted better by all methods;

- More research is needed to improve and evaluate the accuracy of digital imagery and laser based methods investigated in this paper. Although 3-D and 2-D surface properties were successfully measured using different methods, the scanned sample volume or area was very small and there is no standard method to compare and evaluate the accuracy of such data;

- CT meter and laser texture scanner can be used to obtain MPD of a small surface area reasonably accurately within 60 seconds, which is typically less than the time required for conducting a sand patch test. Sand patch test and these methods are not capable of predicting macrotexture of continuous long highway pavements rapidly. Due to the time and traffic control needed to use these methods, the 2-D laser profiler may be superior due to its quickness, relative ease of operation, and relative accuracy of predicting macrotexture;
- As expected, friction resistance increased with increasing surface macrotexture. Coefficient of friction was found to be relatively constant between speeds of 20 and $60 \mathrm{~km} / \mathrm{h}$, with slight decreases occurring as the speed increased between those speeds;

- A linear relationship is developed for nonporous surfaces that can be used to predict normalized friction resistance (IFI) at slip speed of $60 \mathrm{~km} / \mathrm{h}$ (F60) as a function of ETD. In this paper, ETD was obtained from the data measured by the CT meter.

\section{Acknowledgments}

Funding for this research was provided by the Ohio Department of Transportation (ODOT); this is gratefully acknowledged. The contents of this paper reflect the view of the authors and do not necessarily reflect the official views or policies of the sponsor or other entities. Asphalt and concrete samples were created by Kokosing Materials Inc. and by ODOT, respectively. The CT meter and dynamic friction tester were provided for use by Burns, Cooley, Dennis, Inc. of Ridgeland, Mississippi through the Federal Highway Administration loan program. The authors thank these entities and the Ohio State University Center for Automotive Research, Dynatest, and Ames Engineering Inc.

\section{References}

ASTM E965 Standard test method for measuring pavement macrotexture depth using a volumetric technique. Book of ASTM Standards, Vol. 04.03, 1996 (Reapproved 2006). ASTM International. 3 p.

ASTM E1845 Standard practice for calculating pavement macrotexture mean profile depth. Book of ASTM Standards, 2001 (Reapproved 2005). ASTM International. 4 p. 
ASTM E1911 Standard test method for measuring paved surface frictional properties using the dynamic friction tester. Book of ASTM Standards, 1998 (Reapproved 2009). ASTM International. 5 p.

ASTM E1960 Standard practice for calculating international friction index of a pavement surface. Book of ASTM Standards, 1998 (Reapproved 2007). ASTM International. $5 \mathrm{p}$.

ASTM E2157 Standard test method for measuring pavement macrotexture properties using the circular track meter. Book of ASTM Standards, 2001 (Reapproved 2005). ASTM International. 5 p.

Dahir, S. H.; Grambling, W. L. 1990. Wet-pavement safety programs. NCHRP Synthesis of Highway Practice 15, Washington, DC: TRB, National Academies. 54 p.

Ergun, M.; Iyinam, S.; Iyinam, A. F. 2005. Prediction of road surface friction coefficient using only macro- and microtexture measurements, Journal of Transportation Engineering ASCE 131(4): 311-319. http://dx.doi.org/10.1061/(ASCE)0733-947X(2005)131:4(311)

Fisco, N. R. 2009. Comparison of macrotexture measurement methods. Master Thesis. The Ohio State University, Ohio.

Henry, J. J.; Abe, H.; Kameyama, S.; Tamai, A.; Kasahara, A.; Saito, K. 2000. Determination of the international friction index (IFI) using the Circular Texture Meter (CTM) and the Dynamic Friction Tester (DFT), in SURF 2000: Fourth International Symposium on Pavement Surface Characteristics on Roads and Airfields, 2000, Nantes, France, 109-121.

Meegoda, J. N.; Rowe, G. M.; Jumikis, A. A.; Hettiarachchi, C. H.; Bandara, N.; Gephart, N. C. 2005. Estimation of surface macrotexture in hot mix asphalt concrete pavements using laser data, ASTM Journal of Testing and Evaluation 33(5): 1-11.

Moore, D. S.; McCabe, G. P.; Craig, B. A. 2009. Introduction to the practice of statistics. 6th ed. New York: W. H. Freeman and Company. 820 p.

Prowell, B. D.; Hanson, D. I. 2005. Evaluation of circular texture meter for measuring surface texture of pavements, Transportation Research Record 1929, Washington, DC: TRB, National Academies. 88-96.

Sezen, H.; Fisco, N.; Luff, P. 2008. Validation of ODOT's laser macrotexture system. Columbus, Ohio: $\mathrm{OH}$ University, Department of Transportation. $158 \mathrm{p}$.

Snyder, M. B. 2007. Current perspectives on pavement surface characteristics, $R \& T$ Update: Concrete Pavement Research and Technology, Number 8.02.

Halil SEZEN. Associate Professor in the Department of Civil and Environmental Engineering and Geodetic Science at the Ohio State University, Columbus, OH, USA. He got his BS, MS and Ph.D. degrees from the Middle East Technical University, Ankara, Turkey, Cornell University, New York, and University of California, Berkeley, respectively.

Nicholas FISCO. Structural Engineer with the TranSystems Corporation in Cleveland, OH, USA. He got his Master's degree from the Ohio State University in 2009. 